\title{
Lack of cause-effect evidence for the association between exercise and mortality: a true scientific debate for a false clinical issue
}

\author{
Ausência de evidências científicas no tocante à associação de causa e efeito entre exercício \\ físico e mortalidade: um debate científico verdadeiro, mas um falso problema clínico
}

\section{AUTHOR'S \\ Philipe de Souto Barreto ${ }^{1,2}$ (D) \\ Kelly Samara Silva ${ }^{3}$ (D) \\ 1 Gerontopole of Toulouse, Institute of Ageing Toulouse University Hospital, Toulouse, France. 2 UPS/Inserm UMR1027, University of Toulouse III, Toulouse, France. \\ 3 Sports School, Federal University of Santa Catarina, Florianopolis, Brazil. \\ CORRESPONDING \\ Philipe de Souto Barreto \\ philipebarreto81@yahoo.com.br \\ Gérontopôle de Toulouse, Institut du Vieil- lissement, 37, Allées Jules Guesde, F-31000 \\ Toulouse, France. \\ DOI}

10.12820/rbafs.23e0035

\section{c) $(9)$}

Copyright: This is an open-access article distributed under the terms of the Creative Commons Attribution License ${ }^{\circledR}$, which permits unrestricted use, distribution, and reproduction in any medium, provided that the original author and source are credited.

\begin{abstract}
A recent debate raises the issue that there is no cause-effect data from well-powered randomized controlled trials showing that exercise decreases mortality. In this opinion article, we further discuss this issue focusing on the definitions of physical activity (PA) and exercise and the clinical meaningfulness of mortality in the context of PA and exercise. In sum, although mortality is a major clinical outcome, the extent to which its risk should guide PA global recommendations and even exercise prescription is probably negligible, in particular for the large majority of healthy individuals. The debate about prescribing exercise on the basis of cause-effect association regarding mortality is a scientific debate rather than a clinical decision discussion. Health professionals should continuing to stimulate sedentary people to increase their PA and to prescribe exercise adapted to the target population as both a preventive strategy and a therapeutic element, focusing in clinical outcomes individuals consider important.
\end{abstract}

Keywords: Physical activity; Exercise; Mortality; Cause-effect association.

RESUMO

Um recente debate na literatura cientifica focalizou-se na ausência de evidências de uma associação de causa-e-efeito entre exercício físico (EF) e redução do risco de mortalidade. Neste ensaio teórico, essa questão é abordada com ênfase em dois aspectos: as definiçôes de atividade física $(A F)$ e EF e, a relevância clínica do desfecho mortalidade no contexto da prática de AF e de EF. Embora a mortalidade constitua um desfecho clinico de extrema importância, sua pertinência no tocante às recomendaçôes de AF e à prescrição de EF é provavelmente infima, particularmente, com relação à grande maioria das pessoas que gozam de uma boa saúde. Dessa forma, este debate pertence mais a esfera científica do que à esfera das decisöes clínicas. Os profissionais de saúde devem continuar aconselhando a prática de $A F$ e orientando o $E F$ voltado para a população-alvo tanto como estratégia preventiva quanto como elemento terapêutico.

Palavras-chave: Atividade física; Exercício físico; Mortalidade; Causalidade.

\section{Introduction}

The association between physical activity (PA) and mortality risk has been largely proven in longitudinal observational studies undertaken in different populations and countries $^{1-3}$. A recent critical appraisal by Kujala ${ }^{4}$ raises a potential issue in the $\mathrm{PA}$-mortality risk association: no cause-effect data from a well-powered randomized controlled trial (RCT) exists. Shiroma and Lee ${ }^{5}$ extended this debate in a companion commentary piece.

In the present opinion article, we would like to promote the debate on two main aspects of the associations of mortality with PA and exercise: the definitions of PA and exercise (theoretical aspect that strongly influence research methodology) and the clinical meaningfulness of mortality in the context of PA and exercise. The methodological limitations of using observational data for inferring a causal relationship (eg, reversal causality, residual confounding) as well as the methodological limitations of performing a several-year-long exercise RCT (eg, increased dropout rates, decreased exercise adherence, increased intervention costs) have been exposed by Kujala ${ }^{4}$ and Shiroma and $\mathrm{Lee}^{5}$ and are out of the scope of the present paper. 


\section{PA or exercise? Why are we still discussing on that?}

Several researchers have already discussed the differences between PA (ie, any body movement performed by the means of muscle contraction and associated energy expenditure) and exercise (ie, a subset of PA which is systematic, repetitive and purposeful) and we will not prolong this debate. However, this difference is crucial when we try to interpret the scientific evidence about the associations of PA and exercise with mortality. Indeed, the relationship between global PA (involving either different PA domains (ie, leisure-time, occupational, housework, commuting) or only leisure-time) and mortality was found in observational longitudinal studies because such an association is impossible to be measured through a RCT design for a simple methodological reason: from the moment we operationalize a specific regimen of body movement (ie, PA) to be used in an interventional study (eg, in a RCT) in order to investigate cause-effect associations, we are no longer examining global or even leisure-time PA, but a specific exercise regime. Even in the case of an educational intervention, in which a health professional stimulates people to be "more physically active", what we examine is not PA, but counselling; the eventual mediation role of increased PA in the explanation of the effects of counselling on mortality risk would be subject to similar limitations than observational data (eg, residual confounding). Indeed, it is plausible to think that, when advised by a health professional to increase PA in order to improve health, people may pay attention to their health as a whole and may not only improve PA levels, but also promote a healthy nutrition, cognitive stimulating activities, and/or monitor cardiovascular risk factors, all of them strongly contributing to reduce mortality risk and improve other health outcomes. Thus, from a methodological point of view, the effect of PA on mortality risk can't be measured by the traditional RCT design; establishing the observational design as a limitation in the investigation of the PA-mortality relationship is therefore scientifically useless. However, attention must be given to the strengths and limitations of each study methodology in order to implement the appropriate methods to properly respond to the research questions.

\section{PA recommendations: is there a mortality issue?}

Although we vigorously defend the idea that PA guidelines should be revisited ${ }^{6,7}$, we must recognize that even if an effect of a specific exercise regimen on mortality risk is found in a well-designed, properly powered RCT, such a major scientific finding will have little or no impact on PA global recommendations. Indeed, public health recommendations on $\mathrm{PA}^{8}$ involves any type of body movement (including housework, occupational, commuting, and leisure-time PA - being not limited exclusively to exercise) and were elaborated for the primary prevention of non-communicable diseases. Independently of their robustness, findings from a given exercise regime, in a single specific population is not enough to modify a message (ie, global PA recommendations) that applies to the large majority of individuals.

Therefore, although mortality constitutes a major health outcome, and although the best exercise regimen able to reduce mortality risk is an exciting research question, it is usefulness for guiding clinical choices in terms of global PA recommendations or even for exercise prescription is unlikely to be important for healthy individuals and for a large proportion of clinical populations. Defining a precise mortality-related exercise regimen would be of crucial importance only for populations in which exercise has proven to either decrease or increase the risk of death, in particular if any element of the exercise regimen (ie, type, frequency, intensity, duration) had been found to increase mortality; to the best of our knowledge, there is no particular stable disease and/or chronic condition for which exercise (any regimen) is fully prohibited due to an increased risk of dying.

\section{Is mortality risk guiding clinical decisions in terms of exercise prescription?}

Mortality is a major clinically meaningful outcome across all ages and populations. However, to what extent this outcome guides clinical decisions and strategies in terms of exercise may vary according to the phenotype characteristics of a given population. The debate about exercise training and risk of mortality has the advantage to be methodologically assessable, although limitations exist for running exercise RCTs aimed at decreasing mortality risk (ie, too long intervention length and sample size, increased costs, etc). As far as we know, no appropriately powered exercise RCT, having mortality as the primary outcome, was undertaken to date (even though the Generation 100 study ${ }^{9}$ is an interesting 5-year exercise RCT for people aged 70 - 76 and having mortality as the primary outcome measure, this study is an on-going phase IIb trial, which means that, although its findings will certainly 
bring important information to this topic, it was not designed to definitively respond to the question "Does exercise training decrease mortality risk?”). Moreover, meta-analysis of exercise RCTs have found no evidence of an effect on mortality ${ }^{10}$.

In this context, what is the importance of obtaining evidence that exercise training indeed reduces the risk of death? To what extent such an information will change clinical practice of health practitioners around the world?

For example, for gerontologists (ie, health professionals and experts working on the aging process and older adulthood), what guides the clinical approach is to help people to do and to be what they have reason to value, which is in full accordance with World Health Organization guidance on healthy aging ${ }^{11}$. It is plausible to think that a similar clinical approach is prioritized in the majority of healthy populations, regardless their age or culture. As a gerontologist, during my past clinical experience as an exercise instructor in a public health program for promoting a physically active lifestyle for adults and older adults, I have never had a user/client/patient asking for postponing his/her death or prolonging his/her life expectancy through exercise, but I have received hundreds of users telling me they would like to "feel better" and "be able to cope in daily activities". A parallel may be made to early ages: PA and exercise is probably not a way for children/adolescents to decrease the risk of early mortality, but may constitute a mean to play with (or without) their colleagues and friends. Therefore, while children and adolescents are concerned about having fun, exploring and having new experiences and challenges through PA, adults and older adults report the well-being and other positive feelings that come from PA practice. It appears individuals do not link PA to mortality risk and this in a lifespan perspective.

\section{Final Considerations}

Mortality is undoubtedly a major clinical outcome. However, the extent to which its risk should guide PA global recommendations and even exercise prescription is probably negligible, in particular for the large majority of healthy individuals. Therefore, the debate about prescribing exercise on the basis of an eventual cause-effect association with longevity (or reduced mortality) is a scientific debate rather than a clinical decision discussion. Based on striking evidence accumulated in the past three decades showing the long-term associations of both PA and exercise with several clinical outcomes, health professionals should continuing to stimulate sedentary people to increase their daily PA levels and to prescribe exercise adapted to the target population as both a preventive strategy and a therapeutic element, focusing in clinical outcomes that individuals consider as being important to them.

As a health professional, you have the option to interpret the absence of a cause-effect association between exercise training and mortality risk as a half empty or half full glass: indeed, for some, it means that exercise is unable to decrease mortality risk, whereas for others this means that exercise does not increase the risk of death. In other words, exercise, ie, an intervention that has shown to improve several health outcomes, in different age ranges and populations, across countries and cultures, such a powerful intervention does not raise the risk of dying for the large majority of people, including clinical populations. We have already chosen our way of observing the "exercise glass". What about you?

\section{Conflict of interest}

The authors declare no conflict of interest.

\section{Contribution of the authors}

Barreto PS, conceived the work; drafted the article; and approved its final version. Silva KS, conceived the work; revised the article critically for important intellectual content; and approved its final version.

\section{References}

1. Arem H, Moore SC, Patel A, Hartge P, Berrington de Gonzalez A, Visvanathan K, et al. Leisure time physical activity and mortality: a detailed pooled analysis of the dose-response relationship. JAMA Intern Med. 2015;175(6):959-67.

2. Moore SC, Patel AV, Matthews CE, Berrington de Gonzalez A, Park Y, Katki HA, et al. Leisure time physical activity of moderate to vigorous intensity and mortality: a large pooled cohort analysis. PLoS Med. 2012;9(11):e1001335.

3. Lear SA, Hu W, Rangarajan S, Gasevic D, Leong D, Iqbal $\mathrm{R}$, et al. The effect of physical activity on mortality and cardiovascular disease in 130000 people from 17 highincome, middle-income, and low-income countries: the PURE study. Lancet. 2017;390(10113):2643-54.

4. Kujala UM. Is physical activity a cause of longevity? It is not as straightforward as some would believe. A critical analysis. Br J Sports Med. 2018;52(14):914-8.

5. Shiroma EJ, Lee I-M. Can we proceed with physical activity recommendations if (almost) no clinical trial data exist on mortality? Br J Sports Med. 2018;52(14):888-9.

6. De Souto Barreto $P$. Time to challenge public health guidelines on physical activity. Sports Med Auckl NZ. 2015;45(6):769-73.

7. Silva KS, Garcia LMT, Rabacow FM, de Rezende LFM, de Sá TH.Physical activity as part of daily living: Moving beyond quantitative recommendations. Prev Med. 2017;96:160-2. 
8. World Health Organization. Global recommendations on physical activity for health. WHO Press; Geneva, Switzerland: p. 58; 2010. http://apps.who.int/iris/bitstream/ handle/10665/44399/9789241599979_eng. pdf;jsessionid= 1CBDDCE1A3C3A5B92EF1BD83D59CA024? sequence $=1$

9. Stensvold D, Viken H, Rognmo Ø, Skogvoll E, Steinshamn $\mathrm{S}$, Vatten L, et al. A randomised controlled study of the long-term effects of exercise training on mortality in elderly people: study protocol for the Generation 100 study. BMJ Open. 2015;5(2):e007519.
10. Guirguis-Blake JM, Michael YL, Perdue LA, Coppola EL, Beil TL. Interventions to Prevent Falls in Older Adults: Updated Evidence Report and Systematic Review for the US Preventive Services Task Force. JAMA. 24 2018;319(16):1705-16.

11. World Health Organization. World report on ageing and health. 2015.

Receibed: 05/09/2018

Approved: 15/10/2018

\section{Quote this article as:}

Barreto PS, Silva KS. Lack of cause-effect evidence for the association between exercise and mortality: a true scientific debate for a false clinical issue. Rev Bras Ati Fis Saúde. 2018;23:e0035. DOI: 10.12820/rbafs.23e0035 